\title{
O DIÁRIO DE AULA COMO REGISTRO REFLEXIVO: UMA INVESTIGAÇÃO SOBRE OS DILEMAS ENFRENTADOS DURANTE O ESTÁGIO SUPERVISIONADO DE BIOLOGIA
}

\author{
Glaucia Britto Barreiros, Dulcinéia Ester Pagani Gianotto \\ Universidade Estadual de Maringá - UEM. Mestrado no Programa de Pós-graduação em Educação para Ciências e a \\ Matemática, Maringá- PR. E-mail: glaucia bb@hotmail.com
}

\section{RESUMO}

As experiências vividas no estágio supervisionado norteiam a construção do perfil do futuro profissional docente. Apenas a leitura de teorias que complementam a pratica do estágio, não é suficiente para desenvolver os saberes docentes e transformar os conhecimentos desses acadêmicos, ações como registrar em diário de aula (DA) suas experiências e pensar sobre estas é uma estratégia para incentivar a prática reflexiva. A pesquisa é qualitativa, e tem por objetivo investigar os acadêmicos de Ciências Biológicas - UEM, no período do estágio supervisionado II. Os dados coletados foram o DA preenchidos com descrições e análises reflexivas dos acadêmicos, além de observações diretas dos acadêmicos. Sobre estes dados foi elaborada a análise de conteúdo com a categorização e discussão presentes nesse artigo (BARDIN, 1977). Os licenciandos relataram dificuldades e impressões dos seus dilemas durante o planejamento, execução e no pós aula. Identificamos nos registros uma relevante similaridade nas linhas de reflexões.

Palavras-chave: Formação inicial, Prática reflexiva, Estagio Supervisionado, Diários de aula.

\section{THE DAILY LESSON AS REFLECTIVE RECORD: AN INVESTIGATION INTO THE DILEMMAS FACED DURING THE SUPERVISED INTERNSHIP OF BIOLOGY}

\begin{abstract}
The supervised training experiences in guiding the construction of teachers' professional future profile. Just reading theories that complement the practice stage, it is not enough to develop teacher knowledge and translate knowledge of these scholars, as actions to journal class (DA) their experiences and think about this is a strategy to encourage the practice reflective. The research is qualitative and aims to investigate the academics of Biological Sciences - EMU in the period of supervised II. The data collected were the DA filled with descriptions and analyzes of academic reflective, and direct observations of academics. About this data was developed content analysis with categorization and discussion presented in this article (Bardin, 1977). The student teachers reported difficulties and dilemmas of his impressions during the planning, execution and post class. Identified in the records relevant similarity in the lines of reflections.
\end{abstract}

Keywords: Initial training, reflective practice, Supervised Internship, Daily lesson. 
INTRODUÇÃO

A formação inicial e continuada dos professores precisa de melhorias e, na busca por qualidade é preciso ultrapassar a barreira dos paradigmas que envolvem a docência: ideias errôneas que se encontram impregnadas no senso comum dos futuros professores. Uma dessas ideias, diz respeito à concepção de muitos professores de que ensinar é um trabalho simples. GilPerez (2009) defende que é preciso, na formação inicial superar esta concepção por meio de uma mudança didática que foca a apropriação de uma concepção de ensino-aprendizagem das Ciências como objeto de construção de conhecimentos. Assim,

[...] "Tal apropriação, para que se possibilite o deslocamento do modelo vigente de transmissão/recepção, deverá estar teoricamente fundamentada e ser fruto de uma vivência reiterada das novas propostas teóricas, além do período necessariamente breve de uma formação inicial. A preparação docente deverá estar associada, dessa maneira, a uma tarefa de pesquisa e inovação permanentes" (GIL-PEREZ, 2009, p. 66).

Além dessas rupturas das visões simplistas sobre o ensino de Ciências que exige uma formação pautada na epistemologia das Ciências. Carvalho (2011) que também partilha desta visão, aponta ainda outras necessidades formativas do professor de Ciências, que são: ter conhecimento sobre o que será ensinado; ser questionador das ideias docentes de senso comum, estudar constantemente as teorias sobre ensino-aprendizagem em Ciências, ser crítico com relação ao "ensino tradicional", saber preparar atividades capazes de promover uma aprendizagem significativa, saber mediar os trabalhos dos alunos, saber avaliar e por fim, buscar uma prática didática de ensino e pesquisa. A autora propõe uma discussão sobre o ensino de Ciências, para transformar o pensamento espontâneo do professor que precisa "saber" e "saber fazer", para uma construção do conhecimento realizada sob as características de uma pesquisa científica que exigem uma investigação, reflexão e compreensão do processo.

Para que esta formação seja significativa Gil-Perez (2003), aponta que é preciso não apenas melhorar o currículo dos cursos de formação docente, mas realizar uma preparação para que estes futuros professores compreendam e se preparem para desenvolver este novo currículo e que sejam capazes de colocar em prática as teorias contemporâneas. Pimenta (2005), ressalta que somente teorias não bastam e que recentemente a formação de professores está com os olhos voltados para a prática pedagógica desse professor, onde o foco é contribuir para a formação da identidade docente. Essa construção do sujeito professor historicamente situado, inicia-se na formação inicial e colabora para o exercício da atividade docente "à posteriori". Para a autora: 
[...] "professorar não é uma atividade burocrática para a qual se adquire conhecimentos e habilidades técnico-mecânicas. Dada a natureza do trabalho docente, que é ensinar como contribuição ao processo de humanização dos alunos historicamente situados, espera-se da licenciatura que desenvolva nos alunos conhecimentos e habilidades, atitudes e valores que thes possibilitem permanentemente irem construindo seus saberes-fazeres docentes a partir das necessidades e desafios que o ensino como prática social lhes coloca no cotidiano" (PIMENTA, 2005, p. 18).

Entende-se que a renovação nas ações dos professores tem sua gênese na formação inicial, durante o estágio supervisionado. O estágio e a instrumentação pedagógica são de extrema importância, pois proporcionam o primeiro contato do licenciando com a escola, são os primeiros testes e experimentações no "laboratório" que a sala de aula se caracteriza. Para desenvolver estas demandas presentes na atividade do professor, os licenciandos precisam desenvolver o que Pimenta (2005), chama de saberes da docência. Segundo a autora estes saberes, iniciam-se pelos saberes da experiência, que são aqueles construídos no cotidiano com a escola, os planejamentos, os colegas, entre outros. Outro saber docente é o do conhecimento, que vai além dos conceitos e mergulha na compreensão do significado de ensinar aquele conteúdo. E por fim os saberes pedagógicos que segundo a autora emanam dos dois anteriores, e que corrobora com a reflexão sobre o que se faz na prática, assim: "A especificidade da formação pedagógica, tanto a inicial como a contínua, não é refletir sobre o que se vai fazer, nem sobre o que se deve fazer, mas sobre o que se faz" (PIMENTA, 2005, p. 26).

Emana aprendizado dessa experiência no estágio supervisionado, os estágios presentes nos currículos das licenciaturas proporcionam debate crítico pelos participantes e incentiva a criatividade e inovação, o ensino assim como a Ciência e a sociedade muda e precisa ser renovada. Assim quando falamos sobre a formação de professores faz necessário abandonar uma racionalidade técnica que não é suficiente para tornar, o ambiente da escola menos tradicional e mais integradora e participativa, condizente com a realidade do aluno. A prática reflexiva é sem dúvida uma vertente bastante estudada que busca a autonomia do professor e o progresso de sua prática, tornando-os mais críticos, para elencarem os saberes a serem ensinados e distinguir quais as formas de se trabalhar em sala de aula, neste sentido a prática reflexiva deve ser incorporada de todas as formas pela formação inicial e continuada (GIANOTTO, 2012). Nesse sentido o conceito da formação de professores de forma reflexiva, que se caracteriza pela valorização da experiência e da reflexão na experiência vivenciada pelos professores é compartilhado por muitos autores (SCHÕN, 1992; FREIRE, 1996; PIMENTA, 2002; ALARCÃO, 2003). 
Nesse sentido introduziu-se os DA, que são registros pessoais que descrevem o antes, durante e depois das atuações em sala de aula. Introduzindo aos participantes a abordagem reflexiva presente nos registros escritos no qual o DA se configura, demonstrando a importância de se escrever para posterior análise e autorreflexão da sua atuação. Além de ser um acervo para a confecção e descrição de um trabalho desenvolvendo assim professores pesquisadores de sua prática. Segundo Zabalza (2004), o diário proporciona acesso ao mudo pessoal, a explicitação dos próprios dilemas, a posterior análise e avaliação do que pode ser reajustado e por fim acarreta no desenvolvimento profissional. Visto que o professor, atuante ou em formação, pode realizar uma autorreflexão de sua atuação, permitindo-Ihe explorar sua prática e identificar possíveis erros e futuras melhorias, tornando se autocrítico e investigador de sua prática, além de um pesquisador do ensino.

Partindo dos princípios teóricos do uso do diário como instrumento da prática pedagógica e dos pressupostos da prática reflexiva na formação de professores, a partir da análise das observações das atuações, descrições e reflexões dos acadêmicos presentes nos diários, faz-se necessário compreender algumas questões como: Como o acadêmico durante as ações do estágio supervisionado utiliza esse diário? Como são as reflexões descritas? O objetivo deste trabalho é analisar como se caracteriza as reflexões dos acadêmicos de Biologia no período do estágio supervisionado II, observando se há uma construção da prática reflexiva por estes participantes.

\section{Metodologia}

A pesquisa é de caráter qualitativo e se configura por investigar e descrever sem preocupação com resultados, mas trazendo como foco o processo da pesquisa e os seus envolvidos, pois se apresenta de maneira subjetiva, onde as variáveis não podem ser controladas (LUDKE \& ANDRÉ, 1986). Este artigo é sobre a formação inicial de professores e busca por contribuir para os estudos sobre a reflexão durante os estágios supervisionados. A pesquisa foi aprovada no Comitê de ética na Pesquisa $(C E P)^{1}$.

Os sujeitos da pesquisa foram doze acadêmicos do curso de Ciências Biológicas da Universidade Estadual de Maringá, durante o período de estágio supervisionado II. Os instrumentos utilizados para o levantamento dos dados foi: DA dos acadêmicos e suas descrições e reflexões sobre as ações de planejamento, execução e pós aulas ministradas. Alguns trechos desses DA foram utilizados nos resultados e discussões, para identifica-los e diferenciá-los enumeramos os 11 diários, estipulando a sigla Diário 1 (D1) até o Diário 11 (D11). Os dados foram submetidos a uma análise de conteúdo utilizando-se do cruzamento entre os dados coletados por

\footnotetext{
${ }^{1}$ Número de protocolo do CEP - CAAE: 25702814.9.0000.0104.
} 
meio da categorização de respostas proposta por Bardin (1977, p. 117), que é "uma operação de classificação de elementos constitutivos de um conjunto, por diferenciação e, seguidamente, por reagrupamento segundo gênero (analogia), com os critérios previamente definidos". Nesse sentido, as descrições dos diários da prática pedagógica foram categorizados a fim de identificar as unidades de significados que demonstrem as visões dos acadêmicos.

\section{RESULTADOS}

QUADRO 1. Principais dificuldades, preocupações e inseguranças relatadas nos diários.

\begin{tabular}{|c|c|c|}
\hline \multicolumn{3}{|l|}{ Durante o planejamento das ações } \\
\hline Trechos & $\begin{array}{c}\text { Diários } \\
\text { encontrados }\end{array}$ & $\%$ \\
\hline "Pensar em uma aula dinâmica" / "forma atrativa" & D1, D9, & $18,18 \%$ \\
\hline "Organização da aula" & D2, D6 & $18,18 \%$ \\
\hline $\begin{array}{l}\text { "Quais recursos didáticos seriam mais apropriados" / } \\
\text { "forma como o conteúdo seria transmitido" / "como } \\
\text { abordar o tema" }\end{array}$ & $\begin{array}{l}\text { D2, D7, D9, } \\
\text { D11 }\end{array}$ & $36,36 \%$ \\
\hline "O tempo" / "ajuste do tempo da aula" & D2, D9 & $18,18 \%$ \\
\hline $\begin{array}{c}\text { "Qual profundidade abordar dos conceitos" / "conteúdo" } \\
\text { / "escolher os tópicos relevantes" }\end{array}$ & $\begin{array}{l}\text { D3, D7, D9, } \\
\text { D11 }\end{array}$ & $36,36 \%$ \\
\hline $\begin{array}{l}\text { "Descobrir o que o aluno já havia estudado ou não" / } \\
\text { "nível do conteúdo dos alunos" }\end{array}$ & D4, D11 & $18,18 \%$ \\
\hline "Como era o comportamento da turma" & D4 & $9,09 \%$ \\
\hline "Sinto insegurança com relação ao feedback dos alunos" & D7 & $9,09 \%$ \\
\hline \multicolumn{3}{|l|}{ Durante a aula } \\
\hline $\begin{array}{c}\text { "Fiquei bastante insegura com as Intervenções da } \\
\text { professora da turma" }\end{array}$ & D1, D8, D10 & $27,27 \%$ \\
\hline $\begin{array}{c}\text { "Realizei algumas brincadeiras para descontrair e } \\
\text { interagir com o alunos" }\end{array}$ & D7, D10 & $18,18 \%$ \\
\hline "Fazer os alunos responderem" & D1 & $9,09 \%$ \\
\hline 'Apresentar um desfecho da aula" & D3 & $9,09 \%$ \\
\hline "Os alunos sabiam muito sobre o conteúdo" & D3, D4, D5 & $27,27 \%$ \\
\hline "Não ocorreu como planejado" & D4, D8 & $18,18 \%$ \\
\hline $\begin{array}{c}\text { "Os alunos responderam as atividades durante a } \\
\text { explicação" }\end{array}$ & D4 & $9,09 \%$ \\
\hline "No início estava um pouco nervosa" / "Insegurança & $\begin{array}{l}\text { D5, D7, D8, } \\
\text { D11 }\end{array}$ & $36,36 \%$ \\
\hline "Apesar de responder ao relatório tinham dúvidas" & D5, D11 & $18,18 \%$ \\
\hline "Um ponto negativo é que sou quieta" & D6 & $9,09 \%$ \\
\hline "O tempo foi um pouco mal administrado" & D7 & $9,09 \%$ \\
\hline $\begin{array}{c}\text { "Infelizmente não pude concluir e demonstrar a prática" } \\
\text { / "a pratica não deu certo" }\end{array}$ & D7, D9 & $18,18 \%$ \\
\hline "Conceitos dos alunos errados" & D8, D10 & $18,18 \%$ \\
\hline "Procurei ser descontraída e engraçada" & D7, D10 & $18,18 \%$ \\
\hline \multicolumn{3}{|l|}{ Após a aula } \\
\hline
\end{tabular}




\begin{tabular}{|c|c|c|}
\hline "Podia ter explicado melhor" & D2 & $9,09 \%$ \\
\hline "Poderia ter questionado mais" & D2 & $9,09 \%$ \\
\hline "Faltou um fechamento" & D4 & $9,09 \%$ \\
\hline $\begin{array}{c}\text { "Professora da turma restringiu um pouco a forma de } \\
\text { trabalhar" }\end{array}$ & D5 & $9,09 \%$ \\
\hline $\begin{array}{c}\text { "Esqueci algumas analogias" } \\
\text { o aluno" }\end{array}$ & D7 & $9,09 \%$ \\
\hline $\begin{array}{c}\text { "Uma única aula é pouco, é preciso criar um vínculo com } \\
\text { "Insegurança de entrar primeira vez em uma sala de }\end{array}$ & D10 & $9,09 \%$ \\
\hline "Poderíamos explorar melhor os recursos disponíveis" & D11 & $9,09 \%$ \\
\hline "O tempo é curto" & D11 & $9,09 \%$ \\
\hline "Deixo registrado o meu receio de ter que dar aula \\
novamente"
\end{tabular}

\section{DISCUSSÃO}

Neste artigo a proposta foi de analisar e identificar os dilemas e reflexões apresentadas pelos licenciandos de Ciências Biológicas durante uma atuação no estágio supervisionado II. As discussões e reflexões foram realizadas à luz de Carvalho (2011) e (Pimenta (2005), além dos pressupostos de Schõn (1992) e Freire (1996) acerca da reflexão sobre a prática docente. A formação inicial de professores no contexto da prática de ensino tem como objetivo realizar melhorias para o Ensino, aumentando a experiência, a troca entre as universidades e as escolas básicas e promover uma transformação na formação destes futuros professores.

Para melhor compreensão colori o quadro acima com o intuito de notarmos que apesar de os acadêmicos refletirem em momentos diferentes existe uma proximidade da linha de reflexão, sobre as dificuldades, preocupações e inseguranças durante a realização de uma aula prática. Após a análise identificamos sete principais aspectos, que dividi em cores no quadro I, para melhor compreensão: Laranja - Buscar aulas dinâmicas, Azul - Organização da aula, Verde - Estratégias para a aula, Vermelho - O tempo, Cinza - Profundidade dos conceitos a serem abordados, Branco - As características dos alunos (nível de conteúdo, participação e disciplina), Roxo - Medos e inseguranças pessoais, estes sete aspectos aparecem nas reflexões dos diários nos três momentos da atuação dos licenciandos, no planejamento, execução e na reflexão posterior as aulas (Quadro I).

Na perspectiva das reflexões encontramos as habilidades citadas por Carvalho (2011) que casam-se com as dificuldades apresentadas pelos acadêmicos, tais como: conhecimento sobre o que será ensinado; criticidade com relação ao "ensino tradicional", saber preparar atividades capazes de promover uma aprendizagem significativa, saber mediar os trabalhos dos alunos, saber 
avaliar e buscar uma prática didática de ensino e pesquisa. Nessa pesquisa buscou-se incentivar os acadêmicos, por meio da escrita nos diários de aula. Segundo Zabalza (2004), ao descrever as atividades no DA o professor já realiza uma autoavaliação e assim os registros transformam-se em pesquisa da própria prática, que promove mudanças e inovações no ensino e na atuação do professor.

Além dessas linhas similares de reflexão apresentadas pelos licenciandos frente a prática vivenciada no estágio. Notamos que $63,63 \%$ (7 acadêmicos) apresentaram uma forma simplista de pensar acerca dos objetivos alcançados durante as suas atuações. Os acadêmicos utilizaram frases como: "ocorreu tudo tranquilamente", "os objetivos da aula foram alcançados", "acredito que os objetivos foram atingidos", "a aula ocorreu bem", entretanto quando vamos analisar no que eles se baseiam para definir essa tranquilidade e essa certeza de alcance das propostas da aula ministrada observamos que eles têm uma visão de senso comum sobre o que é realmente o processo ensino-aprendizagem, ainda resta na visão deles a concepção de conhecimento transmitido pronto e acabado da visão tradicional (CARVALHO, 2011). A aprendizagem do aluno não pode ser mensurada, visto que é algo que não pertence ao professor que é meramente um mediador na construção individual do aluno sobre os conceitos trabalhados durante a aula.

Outra concepção deturpada encontrada nos diários é a de que a problematização é repetitiva e cansativa, quase desnecessária quando os alunos já estão mais avançados no conteúdo a ser trabalhado. Dois acadêmicos $(18,18 \%)$ afirmaram que os levantamentos prévios foram desnecessários. Notamos que o licenciando ainda não tem a ideia formada sobre as diversas funções da problematização junto aos alunos, tais como, interação e integração com o aluno, troca de informação com alunos mais atrasados, avaliação de qual nível de conhecimentos determinados alunos já trazem e quais são os conceitos de senso comum a serem trabalhados.

A visão de senso comum arraigada nas concepções dos docentes, é a de que o papel do professor é fácil. Nesse sentido três acadêmicos $(27,27 \%)$ trazem em suas reflexões as falas: "ensinar é algo muito difícil", "não existe facilidade em nenhuma parte da regência" e "o planejamento é complexo", em que podemos perceber uma fuga dessas visões simplistas do trabalho do professor, apesar de todos de alguma forma citarem uma dificuldade durante o transcorrer dos relatos das atividades, apenas estes expressaram literalmente não concordar com essa falsa visão do trabalho docente.

Realizamos junto a coleta de dados com o diário o acompanhamento das aulas ministradas que eles refletiram. E com essas observações diretas conseguimos notar que os acadêmicos que apontaram mais dificuldades nos relatos dos DA, foram os que menos apresentaram dificuldades 
ao ministrarem as aulas. No aspecto geral todos se saíram bem, exceto três alunos que não conseguiram realizar anteriormente a correção do planejamento junto a orientadora do estágio. A orientação para os primeiros passos dentro da sala de aula é de extrema importância. Porém ao ler os registros desses três acadêmicos notou-se um excesso de confiança e ausência de dificuldades justamente no planejamento. Sem dúvidas acredita-se que de alguma forma está despreocupação e o imprevisto com a correção prejudicarão a aula e constrangeram a experiência, pois foi nesses DA que encontrei a fala: "fiquei bastante insegura com as intervenções da professora da turma".

Por fim, apenas dois acadêmicos (18,18\%) apresentaram além de uma reflexão e autocrítica, a maneira como ele pretendia realizar a mudança para as próximas atuações. Os outros $81,81 \%$ (9 acadêmicos), apresentaram uma reflexão que podemos classificar como média, pois não leva em consideração as críticas do ensino e as teorias que precisam mergulhar para inovarem e compreenderem melhor a prática docente reflexiva. Ainda assim todos de alguma forma citaram que a experiência vivenciada no estágio supervisionado foi boa, e os que se aprofundaram mais defenderam a importância do estágio para a formação de professores.

\section{Conclusão}

Os acadêmicos apresentaram inúmeras dificuldades, preocupações e inseguranças e ao cruzar os relatos nos diferentes momentos refletidos, notamos algumas linhas de reflexões similares. Ainda pudemos observar que o DA foi um instrumento muito importante dentro do processo de formação desses licenciandos, e cumpriu seu papel de levar o aluno a refletir de forma a estimular reflexão na ação proposta por Schõn (1992) e corroboradas por Pimenta (2005), que afirma que para desenvolver os saberes da docência, o inicio deve ser pela experiência.

\section{Referências}

ALARCÃO, Isabel. Professores reflexivos em uma escola reflexiva. Cortez Editora, São Paulo, (2) p. 40-57, 2003.

BARDIN, L. Análise de conteúdo. Lisboa: Edições 70, 1977.

CARVALHO, A. M. P \& GIL-PEREZ, D. Formação de professores de ciências. São Paulo: Editora Cortez, 2011.

FREIRE, Paulo. Pedagogia da autonomia: saberes necessários à prática educativa. São Paulo: Paz e Terra, 1996.

GIANOTTO, D. E. P. et al (org.) Formação docente e instrumentalização para o ensino de Ciências professores. Maringá, Eduem, 2012. 
GIL-PÉREZ, Daniel. Formação de professores de Ciências: tendências e inovações. São Paulo: Cortez, 2003.

LUDKE, M.; ANDRÉ, M. E. D. A. Pesquisa em educação: abordagens qualitativas. São Paulo: EPU, 1986.

PIMENTA, Selma Garrido; GHEDIN, Evandro (Orgs.). Professor reflexivo no Brasil: gênese e crítica de um conceito. São Paulo: Cortez, 2002.

PIMENTA, Selma Garrido (Orgs.). Saberes pedagógicos e atividade docente/textos Edson Nascimento Campos [et. al.]; 4o ed. São Paulo: Cortez - 2005.

SCHÖN, D. A. Formar professores como profissionais reflexivos. In: Nóvoa (org.) Os professores e a sua formação, Lisboa, Dom Quixote 1992.

ZABALZA, Miguel Ángel. Diários de aula: um instrumento de pesquisa e desenvolvimento profissional. Artmed Editora, 2004. 